\title{
Family history and perceptions about risk and prevention for chronic diseases in primary care: A report from the Family Healthware ${ }^{\mathrm{TM}}$ Impact Trial
}

\author{
Louise S. Acheson, MS, MD ${ }^{1,2,3}$, Catharine Wang, MSc, PhD ${ }^{4}$, Stephen J. Zyzanski, PhD ${ }^{1,3}$, \\ Audrey Lynn, PhD $D^{1}$, Mack T. Ruffin, IV, MD, MPH ${ }^{5}$, Robert Gramling, MD, DSc ${ }^{6}$, \\ Wendy S. Rubinstein, MD, PhD ${ }^{7,8}$, Suzanne M. O'Neill, MS, PhD ${ }^{7,9}$, \\ and Donald E. Nease, Jr., MD ${ }^{5}$, for the Family Healthware ${ }^{T M}$ Impact Trial (FHITr) Group
}

\begin{abstract}
Purpose: To determine whether family medical history as a risk factor for six common diseases is related to patients' perceptions of risk, worry, and control over getting these diseases. Methods: We used data from the cluster-randomized, controlled Family Healthware $^{\mathrm{TM}}$ Impact Trial (FHITr). At baseline, healthy primary care patients reported their perceptions about coronary heart disease, stroke, diabetes, and breast, ovarian, and colon cancers. Immediately afterward, intervention group participants used Family Healthware ${ }^{\mathrm{TM}}$ to record family medical history; this web-based tool stratified familial disease risks. Multivariate and multilevel regression analyses measured the association between familial risk and patient perceptions for each disease, controlling for personal health and demographics. Results: For the 2330 participants who used Family Healthware ${ }^{\mathrm{TM}}$ immediately after providing baseline data, perceived risk and worry for each disease were strongly associated with family history risk, adjusting for personal risk factors. The magnitude of the effect of family history on perceived risk ranged from 0.35 standard deviation for ovarian cancer to 1.12 standard deviations for colon cancer. Family history was not related to perceived control over developing diseases. Risk perceptions seemed optimistically biased, with $48-79 \%$ of participants with increased familial risk for diseases reporting that they were at average risk or below. Conclusions: Participants' ratings of their risk for developing common diseases, before feedback on familial risk, parallels but is often lower than their calculated risk based on family history. Having a family history
\end{abstract}

From the ${ }^{1}$ Department of Family Medicine, Case Western Reserve University, Cleveland, Ohio; ${ }^{2}$ Family Medicine Research Division and Department of Reproductive Biology, University Hospitals Case Medical Center, Cleveland, Ohio; ${ }^{3}$ Program in Cancer Prevention and Control, Case Comprehensive Cancer Center, Cleveland, Ohio; ${ }^{4}$ Department of Community Health Sciences, Boston University School of Public Health, Boston, Massachusetts; ${ }^{5}$ Department of Family Medicine, University of Michigan, Ann Arbor, Michigan; ${ }^{6}$ Departments of Family Medicine and Community \& Preventive Medicine, University of Rochester, Rochester, New York; ${ }^{7}$ Department of Medicine, Center for Medical Genetics, NorthShore University HealthSystem (previously named Evanston Northwestern Healthcare), Evanston, Illinois; ${ }^{8}$ Department of Medicine, University of Chicago Pritzker School of Medicine, Chicago, Illinois; and ${ }^{9}$ Division of General Medicine and Center for Genetic Medicine, Feinberg School of Medicine, Northwestern University, Chicago, Illinois.

Louise Acheson, MD, MS, Department of Family Medicine, University Hospitals Case Medical Center, 11100 Euclid Avenue LC 5036, Cleveland, OH 44106-5036. E-mail: louise.acheson@case.edu.

Disclosure: The authors declare no conflict of interest

Submitted for publication September 14, 2009.

Accepted for publication December 26, 2009.

Published online ahead of print March 3, 2010.

DOI: $10.1097 /$ GIM.0b013e3181d56ae6 of a disease increases its salience and does not change one's perceived ability to prevent the disease. Genet Med 2010:12(4): 212-218.

Key Words: family history, risk perception, worry, perceived control, primary care, family medicine, internal medicine, obstetrics and gynecology, prevention, familial risk assessment, informatics, coronary heart disease, stroke, diabetes, colon cancer, breast cancer, ovarian cancer

Eamily history is an important risk factor for many common diseases including breast (BC), ovarian (OC), and colon cancers (CC), diabetes (DM), coronary heart disease (CHD), and stroke (ST). Although taking a brief family history is a routine part of medical care, especially for new patients, systematic, more detailed family history assessment has been difficult to implement in primary care. ${ }^{1-5}$ Recent development of family history tools that can be self-administered and computer assisted has opened the possibility of widespread familial risk assessment for common diseases and personalized prevention plans based on familial risk stratification. ${ }^{4,6,7}$ However, an added challenge in investigating the health effects of using such tools is to account for the ways in which people's lifelong awareness of their family history has affected their health beliefs and behaviors before formal family history assessment. 8 Similarly, improved understanding of health beliefs related to family medical history will be needed when evaluating the utility of predictive, multiplex genetic testing for common diseases. ${ }^{9}$

People's interpretation of their own family history of multifactorial diseases such as cardiovascular disease, diabetes, or cancer is complex; however, it may influence their perceived susceptibility to the disease and actions taken to prevent it. ${ }^{10,11}$ In many theories of health behavior, risk perceptions, worry, and perceived control (ability to take action to prevent disease) are important motivators of preventive behaviors. ${ }^{12-15}$ However, it has been hypothesized that inherited risk in particular may sometimes be perceived as unavoidable, leading to fatalism. ${ }^{16}$ In other cases, people adduce various reasons why they would not be susceptible to diseases that run in their families. ${ }^{11}$ Therefore, when investigating the effects of family history assessment on disease prevention, it is important to understand the relationship of family medical history to people's perceptions of their own risk of various diseases and their ability to take actions to reduce the risk. Studies of these perceptions have often been limited by considering single diseases and have often enrolled people from high risk, referred groups. This article includes quantitative measures of perceived risk, worry, and control, compared with family history for six common diseases, in a large sample of primary care patients. 


\section{METHODS}

\section{Overview of the Family Healthware ${ }^{\mathrm{TM}}$ Impact Trial}

The US Centers for Disease Control and Prevention (CDC) sponsored development and evaluation of Family Healthware $^{\mathrm{TM}}$, a self-administered, web-based questionnaire to collect and display family medical history, categorize familial risk, and deliver tailored prevention messages, prioritized according to the familial risk of six common diseases. ${ }^{17}$ Similar to the US Surgeon General's family history tool, ${ }^{18}$ the website prompts users to record family history for each first and second degree relative. Risk algorithms and family history-tailored prevention messages were added and tested, as previously described. ${ }^{17}$

In 2005-2007, the Family Healthware ${ }^{\mathrm{TM}}$ Impact Trial (FHITr) group (CDC Office of Genomics and Public Health, in a cooperative agreement with investigators at Evanston Northwestern Health care [E], University of Michigan [M], Case Western Reserve University [C], and American Academy of Family Physicians' National Research Network [NRN]) conducted the FHITr, a cluster-randomized evaluation of Family Healthware $^{\mathrm{TM}}$ among patients aged 35-65 years in primary care practices. ${ }^{19}$ Participants from control group practices completed a baseline questionnaire and received brief, generic prevention messages. Participants in intervention group practices completed the same baseline questionnaire, followed by Family Healthware $^{\mathrm{TM}}$, which delivered personalized familial risk and prevention messages. Participants were encouraged to review the information with a clinician. Both groups were contacted 6 months later to complete a follow-up questionnaire, after which control group participants also used Family Healthware ${ }^{\mathrm{TM}}$, so that their familial risks could be compared with the intervention group.

\section{Purpose of these analyses}

This article reports on the relationship between participants' perceptions of personal risk, worry, and control over each disease shortly before recording a detailed family medical history, and the level of familial risk calculated by Family Healthware ${ }^{\mathrm{TM}}$. Cross-sectional analyses of the baseline data from all 2330 participants in the intervention group of FHITr were conducted. Control group participants were excluded from the current analysis, because they did not record their family histories until the end of follow-up, using Family Healthware ${ }^{\mathrm{TM}} 6$ months after the baseline questionnaire. The details of the study methods, ${ }^{19}$ baseline data collection, ${ }^{19,20}$ and Family Healthware ${ }^{\mathrm{TM}_{17}}$ have been described previously. The protocol was approved by Institutional Review Boards at the CDC and each participating institution

\section{Setting and eligibility}

Twenty-three primary care practices ( 3 gynecology, 7 internal medicine, and 13 family practices), affiliated with three academic centers and the American Academy of Family Physicians' National Research Network, systematically invited patients aged 35-65 years into the intervention group. Fourteen practices in Northern Illinois and one each in California, Florida, Montana, New Jersey, Ohio, and Virginia sent invitation letters to consecutive patients aged 35-65 years who had upcoming appointments with their primary care clinicians, while three group practices in Michigan sent invitation letters to the entire potentially eligible patient panels of participating clinicians. ${ }^{19}$ Nonpregnant patients were eligible if they had not been diagnosed with CHD, DM, ST, or cancer. Most were not further screened for eligibility before receiving a letter of invitation.
Medical record review in practices at site E revealed that $13 \%$ of the patients invited did have one or more chronic diseases that excluded them from participating (W. Rubinstein, unpublished data).

\section{Items and instruments}

Participants first completed an on-line questionnaire measuring demographics, self-reported health status (short form 12), personal risk factors (including body mass index [BMI], physical activity, daily fruit and vegetable intake, and smoking), and health perceptions including worry, perceived personal risk, and perceived control over getting each of six common adult diseases: CHD, ST, DM, CC, BC, and OC. Those in the intervention group soon afterward used the web-based Family Healthware ${ }^{\mathrm{TM}}$ questionnaire to record their detailed family medical history of these diseases. Family Healthware ${ }^{\mathrm{TM}}$ stratified familial risk for each disease.

\section{Dependent variables}

Single items using five-point Likert scales measured these constructs for each disease: perceived personal risk: "Compared to most people your age and sex, what would you say your chances are for developing ___ [disease]? (much lower than average to much higher than average)."21,22 Worry: "During the past 4 weeks, how often have you thought about your chances of getting _ ? ('not at all' to 'almost all the time')." 23 Perceived Control: "There's a lot I can do to prevent___disease]. ('strongly disagree' to 'strongly agree')." 24

\section{Family history-based risk stratification}

The algorithms used in Family Healthware ${ }^{\mathrm{TM}}$ to stratify the familial risk of each disease based on family history have been described $^{17}$ and validated for DM and CHD using epidemiologic data. ${ }^{25-28}$ The algorithms take into account number of affected first and second-degree relatives, their genders and ages at diagnosis, and patterns of related diseases. ${ }^{29}$ Familial risk is categorized for each disease, using these algorithms, as weak (i.e., similar to general population risk), moderate (e.g., one first degree relative with the disease diagnosed in middle age), or strong.

\section{Statistical analysis}

We examined the data for homoscedasticity assumption violations and found statistically significant heterogeneous variances for worry and perceived control. However, analysis of log transformed and untransformed data were basically identical; thus, only analyses of the untransformed data are presented here.

To account for multiple hypothesis testing and the correlated nature of health risk perceptions, we chose a multivariate analysis of variance approach to simultaneously analyze perceived risk, worry, and control for each disease. Wilks' lambda criterion was chosen as the omnibus multivariate test statistic. Initially, unadjusted multivariate analysis of variance comparisons were made among the three Family Healthware ${ }^{\mathrm{TM}}$ risk strata for each disease. This was followed by computation of multivariate analyses of covariance to adjust for study site, demographic, and personal risk factors found to confound the unadjusted analyses of perceived risk, worry, and control.

Finally, hierarchical linear regression analyses were conducted, for each perception outcome, to assess the independent contribution of demographic factors, potentially modifiable personal risk factors, and finally, family history risk category. All statistical analyses were conducted using SPSS version 16.0 (Statistical Package for the Social Sciences, 2007). 


\section{RESULTS}

\section{Participant characteristics}

Intervention group practices systematically invited 14,888 patients; 2,650 patients considered themselves eligible and gave consent and 2,330 (15.7\% of those invited and $88 \%$ of those consented) completed the study questionnaires. Participants ranged in age from 35 to 65 years, with a mean of 50 years. Seventy percent were women, 91\% Caucasian (4\% Black, 3\% Asian, and 2\% Hispanic), 72\% college educated (9\% high school or below and 19\% some college or technical school), and $53 \%$ endorsed a household income $>\$ 75,000$. The distribution of familial risk for each disease is shown in Table 1. We have previously published data indicating that female gender and increasing age were the only demographic variables related to increased family history-based risk in this sample. ${ }^{19}$

\section{Correlations of perceived risk, worry, and control}

Among the six diseases, perceived risk was moderately correlated with worry (Pearson correlation coefficients ranged from 0.30 for $\mathrm{OC}$ to 0.53 for $\mathrm{DM}$, all significant at $P<0.001$ ). Higher perceived risk was correlated with lower perceived control for most of the diseases (coefficients ranged from -0.03 for $\mathrm{DM}$ to -0.12 for $\mathrm{BC}$ ). Worry was not significantly correlated with perceived control for most diseases (coefficients ranged from 0.004 for $\mathrm{BC}$ to 0.10 for $\mathrm{DM}$ ). These modest correlations suggest that the items measured distinct constructs, while confirming that it was appropriate to account for some correlation among the perceptions in analyzing their relationship to familial risk.

\section{Relationship of perceptions to family history-based risk categories}

In this sample as a whole, the mean level of perceived risk for each disease (from 2.65 to 2.78 on a scale of 1-5) corresponds to the response: "about the same as average". However, the levels of perceived personal risk for each disease were strongly related to the family history risk category assigned by Family Healthware $^{\mathrm{TM}}$ algorithms. Table 1 shows that family history risk category for each disease remained associated with perceived risk $(P<0.001$ for each disease) when the analyses were adjusted for personal risk factors that are associated with family history, including age, education, BMI, smoking, diet, and physical activity. The effect of family history on perceived risk ranged from 0.35 standard deviation for OC (a small effect but potentially clinically meaningful) ${ }^{30}$ to 1.12 standard deviation (a large effect) for CC.

In general, study participants, themselves free of all six diseases, rarely worried or thought about their chances of developing chronic diseases. (The response option 2 corresponded to "rarely".) However, familial risk category was positively and strongly associated with worry for each disease, after adjustment for personal risk factors and general health, as shown in Table $1(P<0.001$ for each disease except OC). For worry, the clinically significant effect sizes varied from 0.33 standard deviations for ST to 0.75 standard deviations for CC. In contrast, perceived control (ability to prevent the disease) was not related to familial risk category for any disease. Most participants agreed that there is a lot they could do to prevent the diseases, although cancers were seen as less preventable than heart disease, irrespective of family history. ${ }^{20}$

Figure 1 shows the results of stepwise regression analyses of perceived risk for each disease. The percent of the variance in perceived risk that is explained by demographic characteristics such as age, gender, and study site is small. Adding personal health status, BMI, smoking, and physical activity accounts for a large portion of the variability in perceived risk for cardiovascular diseases (18\% for ST and $22 \%$ for heart disease) and diabetes (19\%). Family history-based risk category adds substantial predictive ability, especially for perceived risk of common cancers, explaining $10 \%$ of the variance in perceived risk for diabetes, $8 \%$ for $\mathrm{CC}$, and $16 \%$ for $\mathrm{BC}$, independent of personal characteristics.

Table 2 shows that a majority of people categorized by Family Healthware ${ }^{\mathrm{TM}}$ at increased familial risk of a disease did not consider themselves to have increased risk of developing the disease, compared with most people their age and sex. Even among participants with strong familial risk of a disease, $9 \%$ (BC) to $30 \%$ (ST) perceived themselves having below or much below average risk (not shown separately in table). Thus, although family history was correlated with risk perception, we found evidence of an optimistic bias with $48-79 \%$ of people with a moderate or strong familial risk level still perceiving themselves at average or below average risk. A smaller proportion $(4-12 \%)$ believed themselves at increased risk of a disease despite having average or below average risk based on family history.

\section{DISCUSSION}

In a large sample from primary care, the FHITr found that, for six common diseases, perceived risk and worry about developing the disease are strongly associated with familial risk calculated from detailed family medical history. Regardless of risk level, most disease-free individuals seldom worried or thought about their risk of developing these diseases. Perceived control over preventing these diseases was not associated with family history-based risk.

Several overarching statements can be made based on the study findings and supported by existing literature. First, family history seems to be associated with risk perceptions. ${ }^{31-36}$ This study supports the existing literature by demonstrating the consistency of this finding across several diseases, after adjusting for personal factors that themselves may aggregate in families: i.e., age, gender, education, BMI, and health behaviors (e.g., fruit and vegetable intake, physical activity, and smoking).

Second, the majority of people currently in good health are optimistically biased about their risks for developing common, chronic conditions. Although psychological research has demonstrated that, in general, people feel they are at lower disease risk when compared with others, ${ }^{22,37}$ this study reveals that this bias seems prevalent even among those with a moderate or strong family history of disease. Importantly, these findings remind researchers that even if risk perceptions are correlated with family history, many individuals would still have potential to increase their perceived risk in response to familial risk assessment. However, given some evidence of a protective effect of optimistic bias, for example, a lower cardiovascular disease (CVD) mortality rate observed among men with optimistically biased CVD risk perceptions, ${ }^{38}$ it will be important to understand the circumstances in which heightened awareness of familial risk may or may not benefit health. A net benefit of raising risk awareness may, in part, depend on the perceived availability and efficacy of measures to reduce risk. ${ }^{14}$

A small proportion of participants in this study believed that they were at elevated risk when their familial risk, as assessed by Family Healthware ${ }^{\mathrm{TM}}$, was not increased. Possibly these individuals were aware of personal risk factors other than reported family history. Thus, it was not possible in this study to 
Table 1 Relationship of perceived risk, worry, and perceived control to familial risk computed on the basis of detailed family history

\begin{tabular}{|c|c|c|c|c|}
\hline \multirow[b]{2}{*}{ Family history risk category } & \multirow[b]{2}{*}{$\mathrm{N}(\%)^{b}$} & \multicolumn{3}{|c|}{ Adjusted means and $95 \%$ confidence intervals $^{a}$} \\
\hline & & Perceived risk & Worry & Perceived control \\
\hline \multicolumn{5}{|l|}{ Coronary heart disease } \\
\hline Weak & $947(41)$ & $2.42(2.37-2.48)$ & $1.68(1.62-1.73)$ & $4.32(4.28-4.36)$ \\
\hline Moderate & $615(27)$ & $2.75(2.69-2.82)$ & $1.90(1.82-1.96)$ & $4.33(4.28-4.39)$ \\
\hline Strong & $768(33)$ & $3.01(2.95-3.07)$ & $2.04(1.97-2.10)$ & $4.37(4.32-4.42)$ \\
\hline Total & 2330 & & & \\
\hline$F$ & & 97.0 & 37.7 & 1.12 \\
\hline$P$ & & $<0.001$ & $<0.001$ & 0.326 \\
\hline Effect size (SD) & & 0.69 & 0.43 & 0.07 \\
\hline \multicolumn{5}{|l|}{ Stroke } \\
\hline Weak & $1212(53)$ & $2.52(2.48-2.57)$ & $1.44(1.40-1.49)$ & $4.01(3.96-4.05)$ \\
\hline Moderate & $783(34)$ & $2.74(2.69-2.80)$ & $1.61(1.56-1.66)$ & $4.02(3.96-4.07)$ \\
\hline Strong & $335(14)$ & $2.91(2.83-3.00)$ & $1.71(1.63-1.79)$ & $4.07(3.98-4.16)$ \\
\hline Total & 2330 & & & \\
\hline$F$ & & 36.16 & 20.11 & 0.82 \\
\hline$P$ & & $<0.001$ & $<0.001$ & 0.443 \\
\hline Effect size (SD) & & 0.43 & 0.33 & 0.08 \\
\hline \multicolumn{5}{|l|}{ Diabetes } \\
\hline Weak & $1426(61)$ & $2.41(2.36-2.46)$ & $1.43(1.39-1.48)$ & $4.08(4.04-4.12)$ \\
\hline Moderate & $643(28)$ & $3.00(2.93-3.06)$ & $1.75(1.69-1.81)$ & $4.15(4.08-4.21)$ \\
\hline Strong & $261(11)$ & $3.30(3.20-3.41)$ & $1.96(1.86-2.06)$ & $4.13(4.04-4.23)$ \\
\hline Total & 2330 & & & \\
\hline$F$ & & 176.51 & 63.62 & 1.62 \\
\hline$P$ & & $<0.001$ & $<0.001$ & 0.198 \\
\hline Effect size (SD) & & 0.86 & 0.59 & 0.06 \\
\hline \multicolumn{5}{|l|}{ Colon cancer } \\
\hline Weak & $2015(88)$ & $2.60(2.57-2.64)$ & $1.36(1.33-1.39)$ & $3.80(3.76-3.83)$ \\
\hline Moderate & $263(11)$ & $3.26(3.16-3.35)$ & $1.68(1.59-1.76)$ & $3.85(3.75-3.95)$ \\
\hline Strong & $52(2)$ & $3.53(3.32-3.74)$ & $1.90(1.71-2.09)$ & $3.89(3.66-4.11)$ \\
\hline Total & 2330 & & & \\
\hline$F$ & & 116.33 & 36.49 & 0.73 \\
\hline$P$ & & $<0.001$ & $<0.001$ & 0.484 \\
\hline Effect size (SD) & & 1.12 & 0.75 & 0.11 \\
\hline \multicolumn{5}{|l|}{ Breast cancer (women only) } \\
\hline Weak & $1251(76)$ & $2.72(2.68-2.76)$ & $1.83(1.78-1.88)$ & $3.32(3.27-3.38)$ \\
\hline Moderate & $233(14)$ & $3.45(3.36-3.54)$ & $2.17(2.05-2.29)$ & $3.27(3.15-3.40)$ \\
\hline Strong & $172(10)$ & $3.58(3.47-3.69)$ & $2.26(2.12-2.39)$ & $3.26(3.12-3.40)$ \\
\hline Total & 1656 & & & \\
\hline$F$ & & 179.10 & 26.19 & 0.52 \\
\hline$P$ & & $<0.001$ & $<0.001$ & 0.597 \\
\hline Effect size (SD) & & 1.05 & 0.46 & $\begin{array}{l}0.06 \\
\text { (Continued) }\end{array}$ \\
\hline
\end{tabular}


Table 1 Continued

Adjusted means and $95 \%$ confidence intervals ${ }^{a}$

\begin{tabular}{|c|c|c|c|c|}
\hline \multirow{2}{*}{ Family history risk category } & \multirow[b]{2}{*}{$\mathrm{N}(\%)^{b}$} & & & \\
\hline & & Perceived risk & Worry & Perceived control \\
\hline \multicolumn{5}{|l|}{ Ovarian cancer (women only) } \\
\hline Weak & $1383(9)$ & $2.75(2.72-2.79)$ & $1.42(1.38-1.46)$ & $2.97(2.92-3.02)$ \\
\hline Moderate & $84(6)$ & $3.17(3.03-3.31)$ & $1.65(1.49-1.81)$ & $2.97(2.78-3.17)$ \\
\hline Strong & $56(4)$ & $2.99(2.81-3.16)$ & $1.56(1.36-1.76)$ & $3.03(2.80-3.27)$ \\
\hline Total & $1523^{c}$ & & & \\
\hline$F$ & & 19.05 & 4.55 & 0.13 \\
\hline$P$ & & $<0.001$ & 0.011 & 0.875 \\
\hline Effect size (SD) & & 0.35 & 0.18 & 0.07 \\
\hline
\end{tabular}

$\overline{{ }^{a}}$ The means listed above are all adjusted for the following covariates: gender, age, global health status, fruit and vegetable intake, minutes per week of physical activity, smoking (never, former, and current smoker), body mass index, education, and practice site. Unadjusted means (not shown) are similar to the adjusted means.

${ }^{b}$ Percents may not add to $100 \%$ because of rounding.

${ }^{c}$ Total $\mathrm{N}$ is lower for ovarian cancer, because women who had had both ovaries removed were not asked about perceived risk for ovarian cancer, worry, or control.

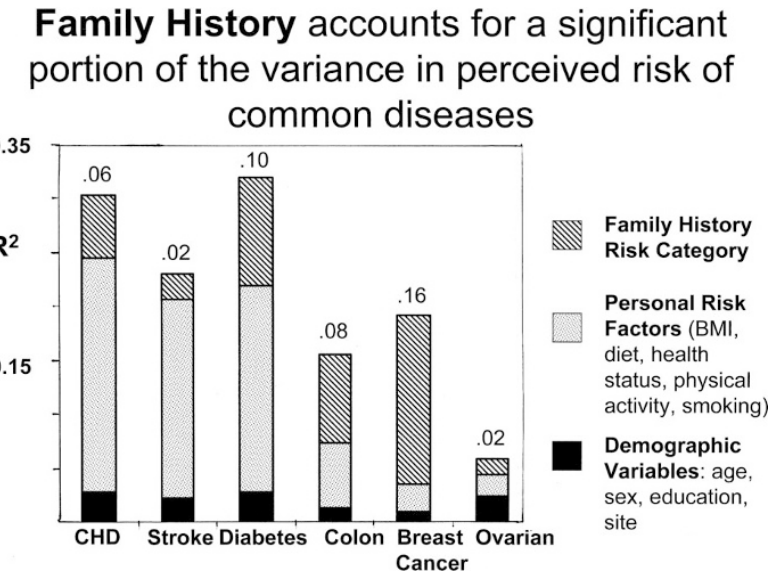

Fig. 1. Proportion of variation in perceived risk explained by demographic, personal risk factors, and family history risk categories. Graph shows $R^{2}$ from stepwise regression analyses for each disease. Numbers above each bar refer to the variance in perceived risk associated with family history risk category. Risk perception for BC and OCs was measured only for women; OC risk perception was measured only for women with ovaries.

determine whether these individuals were pessimistically biased or relatively accurate in their risk perceptions.

Third, for study participants as a group, the strength of family history does not seem to be associated with perceptions of disease controllability. This finding, among people aware of their family medical history at baseline, may allay concerns that conveying information about familial or hereditary risk could increase fatalistic beliefs. ${ }^{39}$ More recent evidence suggests that learning about familial or hereditary risk for diseases such as diabetes does not increase fatalism and may even increase perceptions of control. ${ }^{40}$

\section{Limitations}

This study had several limitations. Single-item measures for perceived risk, worry, and control were used in efforts to minimize response burden when assessing perceptions across six diseases. These measures may not have captured the full range of variability in health perceptions. As participants were selected for absence of the six diseases, they are healthier than many middle-aged patients seen in primary care; the effect of freedom from these chronic diseases on health perceptions could not be measured.

Many middle-aged patients seeing primary care physicians have chronic diseases that would have excluded them from eligibility for this trial. The overall proportion of those invited who would have been eligible to participate in this study (free of all six common diseases) is unknown. However, medical record review in practice at site $\mathrm{E}$ revealed that $13 \%$ of the patients invited did have one or more chronic diseases that excluded them from participating (W. Rubinstein, unpublished data). Nonetheless, over all sites, only $15.7 \%$ of those invited participated in this study, raising concerns about whether their health beliefs are representative. The finding that prevalence of a family history of BC, diabetes, or CHD in these study participants is similar to that in population-based surveys suggests that the sample was not strongly self-selected for higher familial risk. $^{28,41,42}$

Demographics of the study practices (a majority in suburban Chicago) limited the proportion of participants from lower socioeconomic and minority groups and increased the proportion of female participants. It is also likely that use of internet questionnaires selected people more accustomed to computer use, although many patients were offered an option to use a computer in the physician's office or to report measures through a structured telephone interview. The sample is above average in terms of education and income, thus potentially limiting the generalizability of these findings to other populations.

\section{Implications of these findings for practice and research}

Family Healthware ${ }^{\mathrm{TM}}$ and other tools are designed to systematically assess family medical history to target preventive efforts to families at increased risk for diseases. Baseline data from FHITr indicate that self-reported family history of a disease has a clinically important (moderate to large) association with unaffected individuals' perceived risk of developing the disease, and a moderate effect on frequency of thinking about 
Table 2 Proportion of participants who perceived themselves at average or below average risk despite a moderate or strong family history risk

\begin{tabular}{lccc}
\hline Disease & $\begin{array}{c}\text { N at moderate or strong familial } \\
\text { risk, according to Family } \\
\text { Healthware }\end{array}$ & $\begin{array}{c}\text { Percentage of N who perceived themselves } \\
\text { at above or much above average risk } \\
\text { (before using Family Healthware) }\end{array}$ & $\begin{array}{c}\text { Percentage of N who perceived } \\
\text { themselves at average or } \\
\text { below average risk }\end{array}$ \\
\hline Coronary heart disease $^{a}$ & 1383 & 30 & 70 \\
Stroke $^{a}$ & 1118 & 21 & 79 \\
Diabetes $^{a}$ & 904 & 40 & 60 \\
Colon cancer $^{a}$ & 315 & 46 & 54 \\
Breast cancer $^{b}$ & 405 & 52 & 48 \\
Ovarian cancer $^{c}$ & 140 & 30 & 70 \\
${ }^{a}$ Total $=2330$ men and women. & & & \\
${ }^{b} 1656$ women. & & & \\
${ }^{c} 1523$ women with ovaries. & & & \\
\hline
\end{tabular}

their chances of developing it, before answering any questions about family history. Thus, interventions to increase patients' awareness of disease risk based on family history may encounter a ceiling effect as a result of people's lifelong awareness of their family medical history. Nonetheless, to the extent that clinicians are often unaware, particularly of familial cancer risk, family history assessment in the clinical context could affect clinician awareness and recommendations. ${ }^{43-45}$

The availability of self-administered family history assessment tools expands the feasibility of studying the relationship between family history perceptions and risk-reducing actions, both unprompted and in response to interventions targeted to familial risk. So far, most data on this have come from selected high-risk groups. The findings of this study, consistent with Walter and Emery's interview study of British GP patients, ${ }^{11}$ suggest that fatalistic beliefs with regard to family history of several common diseases are not prevalent among healthy, relatively well-to-do primary care patients (see also, McBride et al. ${ }^{9}$ ). Analyses of follow-up data from FHITr will show whether family history-based prevention messages affected preventive behaviors or changed perceptions about disease risk and prevention.

\section{ACKNOWLEDGMENTS}

The Family Healthware Impact Trial (FHITr) Group consists of the following collaborators: From the CDC: Paula W. Yoon, $\mathrm{ScD}, \mathrm{MPH}$; Rodolfo Valdez, PhD; Margie Irizarry-De La Cruz, MPH; Muin J. Khoury, MD, PhD; Cynthia Jorgensen, Dr PH. From the Rand Corporation: Maren T. Scheuner, MD, MPH. From Northshore University HealthSystem, Evanston, IL: Suzanne M. O'Neill, MA, MS, PhD, Principal Investigator; Wendy S. Rubinstein, MD, PhD, Principal Investigator; Nan Rothrock, PhD; Jennifer L. Beaumont, MS; Shaheen Khan, MS, MBA, MPH; Dawood Ali, MS. From the University of Illinois at Chicago: Erin J. Starzyk, MPH. From Boston University School of Public Health: Catharine Wang, PhD, MSc. From the University of Michigan: Mack T. Ruffin, IV, MD, MPH, Principal Investigator; Donald E. Nease, Jr., MD, Principal Investigator. From Case Western Reserve University, University Hospitals Case Medical Center: Louise S. Acheson, MD, MS, Principal Investigator; Stephen J. Zyzanski, PhD; Georgia L. Wiesner, MD; James Werner, PhD. From the University of Rochester: Robert Gramling, MD, DSc. From the American Academy of Family Physicians' National Research Network:
Wilson D. Pace, MD, Principal Investigator; James M. Galliher, $\mathrm{PhD}$; Elias Brandt, BS, BA.

The Family Healthware ${ }^{\mathrm{TM}}$ Impact Trial (FHITr) was supported through cooperative agreements between the Centers for Disease Control and the Association for Prevention Teaching and Research (ENH-U50/CCU300860 TS-1216) and the American Association of Medical Colleges (UMU36/CCU319276 MM-0789 and CWR U36/CCU319276 MM0630). Dr. Acheson received salary support from NCI K07 CA86958 in Cancer Prevention and Control. None of the authors has a conflict of interest germane to the information presented in this report.

Presented, in part, at the North American Primary Care Research Group Annual Meeting, San Juan, Puerto Rico, November 2008.

\section{REFERENCES}

1. Acheson LS, Wiesner GL, Zyzanski SJ, Goodwin MA, Stange KC. Family history-taking in community family practice: implications for genetic screening. Genet Med 2000;2:180-185.

2. Suther S, Goodson P. Barriers to the provision of genetic services by primary care physicians: a systematic review of the literature. Genet Med 2003;5:70-76.

3. Rich E, Burke W, Heaton CJ, et al. Reconsidering the family history in primary care. J Gen Intern Med 2004;19:273-280.

4. Qureshi N, Wilson B, Santaguida P, et al. Collection and use of cancer family history in primary care. Rockville, MD: Agency for Healthcare Research and Quality, 2007.

5. Hughes K. Health IT-based strategies for studying the use of family history in primary care (abstract). In: NIH State-of-the-Science Conference: Family History and Improving Health. Bethesda, MD: National Institutes of Health, 2009:87-90.

6. Feero WG, Bigley MB, Brinner K; Family Health History Multi-Stakeholder Workgroup of the American Health Information Community. New standards and enhanced utility for family health history information in the electronic health record: an update from the American Health Information Community's Family Health History Multi-Stakeholder Workgroup. J Am Med Inform Assoc 2008;15:723-728.

7. Yoon PW, Scheuner MT, Khoury MJ. Research priorities for evaluating family history in the prevention of common chronic diseases. Am J Prev Med 2003 2003;24:128-135.

8. Acheson L. Research challenges in assessing risk with family history (abstract). In: NIH State-of-the-Science Conference: Family History and Improving Health. Bethesda, MD: National Institutes of Health, 2009:31-34.

9. McBride CM, Alford SH, Reid RJ, Larson EB, Baxevanis AD, Brody LC. Characteristics of users of online personalized genomic risk assessments: implications for physician-patient interactions. Genet Med 2009;11:582 687.

10. Walter FM, Emery J, Braithwaite D, Marteau TM. Lay understanding of familial risk of common, chronic diseases: a systematic review and synthesis of qualitative research. Ann Fam Med 2004;3:583-594. 
11. Walter FM, Emery J. 'Coming down the line'- patients' understanding of their family history of common chronic disease. Ann Fam Med 2005;3: 405-414.

12. Becker M. The health belief model and personal health behavior. Health Educ Monogr 1974;2:324-473.

13. Janz NK, Becker MH. the health belief model: a decade later. Health Educ $Q$ 1984;11:1-47.

14. Witte K. Putting the fear back into fear appeals: the extended parallel process model. Commun Monogr 1992;61:113-134.

15. Vernon SW. Risk perception and risk communication for cancer screening behaviors: a review. J Natl Cancer Inst Monogr 1999;25:101-119.

16. Senior V, Marteau T, Weinman J. Impact of genetic testing on causal models of heart disease and arthritis: an analogue study. Psychol Health 2000;14:1077-1088.

17. Yoon PW, Scheuner MT, Jorgensen C, Khoury MJ. Developing family Healthware, a family history screening tool to prevent common chronic diseases. Prev Chronic Dis 2009;6:A33.

18. My Family Health Portrait. A tool from the Surgeon General. Available at: https://familyhistory.hhs.gov/fhh-web. Accessed May 15, 2009.

19. O’Neill SM, Rubinstein WS, Wang C, et al; Family Healthware Impact Trial group. Familial risk for common diseases in primary care: the Family Healthware Impact Trial. Am J Prev Med 2009;36:506-514.

20. Wang C, O'Neill SM, Rothrock N, et al; Family Healthware Impact Trial (FHITr) group. Comparison of risk perceptions and beliefs across common chronic diseases. Prev Med 2009;48:197-202.

21. Weinstein N. Unrealistic optimism about future life events. J Person Soc Psychol 1980;39:806-820.

22. Weinstein N. Unrealistic optimism about susceptibility to health problems. J Behav Med 1982;5:441-460.

23. Anderson MR, Smith R, Meischke H, Bowen D, Urban N. Breast cancer worry and mammography use by women with and without a family history in a population-based sample. Cancer Epidemiol Biomarkers Prev 2003; $12: 314-320$

24. Witte K, Cameron KA, McKeon JK, Berkowitz JM. Predicting risk behaviors: development and validation of a diagnostic scale. J Health Commun 1996;1:317-341.

25. Hariri S, Yoon P, Qureshi N, Valdez R, Scheuner MT, Khoury MJ. Family history of type 2 diabetes: a population-based screening tool for prevention? Genet Med 2006;8:102-108.

26. Hariri S, Yoon PW, Moonesinghe R, Valdez R, Khoury MJ. Evaluation of family history as a risk factor and screening tool for detecting undiagnosed diabetes in a nationally representative survey population. Genet Med 2006; $8: 752-759$.

27. Scheuner MT, Whitworth WC, McGruder H, Yoon PW, Khoury MJ Expanding the definition of a positive family history for early-onset coronary heart disease. Genet Med August 2006;8:491-501.

28. Scheuner MT, Whitworth WC, McGruder H, Yoon PW, Khoury MJ Familial risk assessment for early-onset coronary heart disease. Genet Med 2006;8:525-531.

29. Scheuner MT, Wang SJ, Raffel LJ, Larabell SK, Rotter JI. Family history: a comprehensive genetic risk assessment method for the chronic conditions of adulthood. Am J Med Genet 1997;71:315-324
30. Middel B, Stewart R, Bouma J, van Sonderen E, van den Heuvel W. How to validate clinically important change in health-related functional status. Is the magnitude of the effect size consistently related to magnitude of change as indicated by a global question rating? J Eval Clin Pract 2001;7:399-410.

31. Kelly K, Ferketich A, Sturm A, et al. Cancer risk and risk communication in urban, lower-income neighborhoods. Prev Med 2009;48:392-396.

32. Jacobsen PB, Lamonde LA, Honour M, Kash K, Hudson PB, Pow-Sang J. Relation of family history of prostate cancer to perceived vulnerability and screening behavior. PsychoOncology 2004;13:80-85.

33. Montgomery GH, Erblich J, DiLorenzo T, Bovbjerg DH. Family and friends with disease: their impact on perceived risk. Prev Med 2003;37: 242-249.

34. Hay J, Coups E, Ford J. Predictors of perceived risk for colon cancer in a national probability sample in the United States. J Health Commun 2006; 11(suppl 1):71-92.

35. Robb K, Miles A, Wardle J. Demographic and psychosocial factors associated with perceived risk for colorectal cancer. Cancer Epidemiol Biomarkers Prev 2004;13:366-372.

36. Katapodi MC, Dodd MJ, Lee KA, Facione NC. Underestimation of breast cancer risk: influence on screening behavior. Oncol Nurs Forum 2009;36: $306-314$.

37. Weinstein ND. Unrealistic optimism about susceptibility to health problems: conclusions from a community-wide sample. J Behav Med 1987;10: 481-500.

38. Gramling R, Klein W, Roberts M, Waring ME, Gramling D, Eaton CB. Self-rated cardiovascular risk and 15-year cardiovascular mortality. Ann Fam Med 2008;6:302-306.

39. Senior V, Marteau TM, Peters TJ. Will genetic testing for predisposition for disease result in fatalism? A qualitative study of parents responses to neonatal screening for familial hypercholesterolaemia. Soc Sci Med 1999; 48:1857-1860

40. Pijl M, Timmermans DR, Claassen L, et al. Impact of communicating familial risk of diabetes on illness perceptions and self-reported behavioral outcomes: a randomized controlled trial. Diabetes Care 2009;32:597-599.

41. Ramsey SD, Yoon P, Moonesinghe R, Khoury MJ. Population-based study of the prevalence of family history of cancer: implications for cancer screening and prevention. Genet Med 2006;8:571-575.

42. Valdez R, Yoon PW, Liu T, Khoury MJ. Family history and prevalence of diabetes in the US population: 6-year results from the National Health and Nutrition Examination Survey (NHANES, 1999-2004). Diabetes Care 2007;30:17-32.

43. Frezzo TM, Rubinstein WS, Dunham D, Ormond KE. The genetic family history as a risk assessment tool in internal medicine. Genet Med 2003;5: $84-91$.

44. O'Neill S, Starzyk E, Kattezham R, WS R. Comparison of family Healthware $^{\mathrm{TM}}$ and physicians' family history documentation among 1124 patients (abstract). Presented at the American Society of Human Genetics Annual Meeting. Philadelphia, PA, 2008.

45. Emery J, Morris H, Goodchild R, et al. The GRAIDS trial: a cluster randomized controlled trial of computer decision support for the management of familial cancer risk in primary care. Br J Cancer 2007;97:486493. 